\title{
Synthesis, Characterization and Blood Based Toxic Effects of Superparamagnetic Nanoparticles
}

\author{
Muhammad Javid ARSHAD ${ }^{1 *}$, Saddique AMIR ${ }^{1}$, Mehmood ZAHID $^{2}$, Amin NIAMA ${ }^{3}$, \\ Husain FAYYAZ ${ }^{4}$, Muhammad Anjum NAEEM ${ }^{5}$, Saeed Ahmad BUZDAR ${ }^{5}$, \\ Muhammad IMRAN 6
}

\author{
${ }^{1}$ Department of Basic Sciences (Physics), University of Engineering and Technology, Taxila, Pakistan, 47050 \\ ${ }^{2}$ Department of Software Engineering, University of Engineering and Technology, Taxila, Pakistan, 47050 \\ ${ }^{3}$ Department of Physics, COMSATS Institute of Information Technology, Lahore, 22060 \\ ${ }^{4}$ Department of Physics, Bahudin Zakariya University, Multan, Pakistan, 60800 \\ ${ }^{5}$ Department of Physics, The Islamia University of Bahawalpur, Pakistan, 63100 \\ ${ }^{6}$ Department of Physics, Government College University, Faisalabad, Pakistan, 3800 \\ crossref http://dx.doi.org/10.5755/j01.ms.25.4.21149
}

Received 20 August 2018; accepted 11 October 2018

\begin{abstract}
The objective of this study is to the assess toxicity of superparamagnetic nanoparticles within normal and diabetic human blood groups using complete blood count (CBC). For this purpose, iron oxide nanoparticles (IONPs) were synthesized by co-precipitation method. Samples were characterized by XRD, SEM, EDS, VSM and CBC. XRD confirmed the cubic structure of $\mathrm{Fe}_{3} \mathrm{O}_{4}$ with Miller indices (2 $\left.\begin{array}{lll}2 & 0\end{array}\right),\left(\begin{array}{lll}2 & 2 & 0\end{array}\right),\left(\begin{array}{lll}3 & 1 & 1\end{array}\right),\left(\begin{array}{lll}4 & 0 & 0\end{array}\right),\left(\begin{array}{lll}4 & 4 & 0\end{array}\right)$ and average size of magnetic nanoparticles was calculated about $11.13 \mathrm{~nm}$ diameter. The morphology of $\mathrm{Fe}_{3} \mathrm{O}_{4}$ nanoparticles was investigated by scanning electron microscope (SEM). SEM images of magnetite were found partially smooth. Spectra of EDX depicted the $\mathrm{Fe}, \mathrm{O}$ and $\mathrm{Cl}$ elements in IONP. Magnetic properties were examined by vibrating sampling magnetometer (VSM). The blood toxicity was reported by blood contents in normal and diabetic blood samples for specified intervals using CBC technique. One sample test of variance of hemoglobin, erythrocytes, leucocytes and thrombocytes showed the significant difference $(\mathrm{p}>0.05)$ among 0 hrs to $72 \mathrm{hrs}$ for all normal and diabetic blood samples. This study concluded that presence of iron oxides nanoparticles of size $11.13 \mathrm{~nm}$ in human blood induces reactive oxygen species which cause the cell death. Hemoglobin was highly affected content of blood than erythrocytes, leucocytes by toxic effects of IONPs. Reduction of platelets among all content of blood groups posed another signature of this hematology study. Toxic spectrum of IONPs must be considered before the application of MRI contrast agents and drug delivery.

Keywords: iron oxides nanoparticles, complete blood count, hemoglobin, erythrocytes, leucocytes.
\end{abstract}

\section{INTRODUCTION}

In biomedical research, superparamagnetic nanoparticles have been approved by Food and Drug Administration U.S.A for in vivo applications such as artificial implants, targeted drug delivery, cell separation, hyperthermia, MRI contrast agents in the imaging of the vasculature and lymph nodes $[1,2]$. Iron oxide nanoparticles deal unique chemical, biological and magnetic properties like chemical stability, biocompatibility and high saturation magnetization. The relaxivity of MNPs depends upon on their size concentration and change the saturation magnetization. More than $50 \mathrm{~nm}$ particles are emerged out from body through reticuloendothelial system [3]. Therefore, iron oxide nanoparticles less than $20 \mathrm{~nm}$ are preferred for MRI contrast agents. However, many nano sized materials are reactive or catalytic and may be potentially toxic. They can easily penetrate through cell membrane and other biological barriers into living organisms and cause cellular dysfunction [4]. Reactive oxygen species (ROS) originate from the transmission of energy or electrons to oxygen is

\footnotetext{
* Corresponding author. Tel.: +92 3336345363 .

E-mail address: arshadrahictn@gmail.com (M.J. Arshad)
}

extremely reactive and probably lethal to living organisms [5]. ROS induces oxidative stress which causes cells failure to maintain normal physiological functions of DNA that leads to cell death. This ROS is produced either by Fenton reaction or by Haber-Weiss cycle reaction [6]. Fenton reaction is an important mechanism of nanoparticle toxicity that generates the high ROS. Iron nanostructures containing $\mathrm{Fe}^{\circ}$ and $\mathrm{Fe}$ (II) could directly reduce molecular oxygen dissolved in the aqueous solution to generate ROS or other complexes through a homogeneous or heterogeneous mechanism Fenton reaction, which involves one-electron reduction of hydrogen peroxide by soluble ferrous iron species, generates hydroxyl radicals that are powerful enough to oxidize most organic molecules as shown in Eq. 1 [7]:

$\mathrm{Fe}^{2+}$-EDTA $+\mathrm{H}_{2} \mathrm{O}_{2} \rightarrow \mathrm{Fe}^{3+}$-EDTA $+\mathrm{OH}^{-}+\mathrm{OH}$.

The Haber-Weiss reaction induces hydroxyl radicals from hydrogen peroxide and superoxide by soluble ferric iron species through following reactions as mentioned in Eq. 2 - Eq. 5. The homogeneous Fe(II) autoxidation in the presence of molecular oxygen in the aqueous solution via single-step two electron transfer or stepwise one electron transfer reactions can generate oxidants of ferryl-oxo complexes or a series of ROS [8]. 
$\mathrm{Fe}^{3+}+\mathrm{e}^{-} \rightarrow \mathrm{Fe}^{2+}$

$\mathrm{O}_{2}+2 \mathrm{H}^{+} 2 \mathrm{e} \rightarrow \mathrm{H}_{2} \mathrm{O}_{2}$;

$\mathrm{Fe}^{3+}-\mathrm{EDTA}+\mathrm{H}_{2} \mathrm{O}_{2} \rightarrow \mathrm{Fe}^{2+}-\mathrm{EDTA}+\mathrm{O}_{2}^{-}+2 \mathrm{H}_{2} ;$

$\mathrm{Fe}^{3+}-\mathrm{EDTA}+\mathrm{O}_{2}{ }^{-} \leftrightharpoons \mathrm{Fe}^{2+}-\mathrm{EDTA}+\mathrm{O}_{2}$.

A question raises in biomaterial research that how and what type of iron oxides nanoparticles can induce biochemical toxicity [9]. In this perspective, iron oxides nanoparticles pose the long-term effects in accumulation, metabolism and excretion on the base of administration in brain as well as other organs of body. Iron participates in a single oxidation-reduction reaction and it produces highly reactive oxygen spices. This cytotoxicity and interferes of iron oxides with the normal components and functions of the cell [10]. Furthermore, many toxicity reports of iron oxides NPs have been presented a profile considering the particle size, type of surface coating, breakdown products, concentration, the degree of opsonization and cytotoxicity in cells [11].

The CBC test offers a comprehensive assessment of pathology and guides the diagnosis and treatment of almost all diseases. A CBC determines any increases or decreases in cell counts. For instance, low levels of hemoglobin and hemocrit are considered as signs of anemia. Similarly, any abnormal increases or decreases in the number of white blood cells could be a sign of infection, inflammation and cancer. Platelets make blood clot and control bleeding [12-14]. However, toxicity of magnetic nanoparticles varies with size, uncoated and coated concentration of material in biochemical reaction. In this study, we have made an effort to assess the toxic effects of superparamagnetic nanoparticles in blood samples counting hemoglobin, erythrocytes, leucocytes and thrombocytes in healthy as well as diseased blood samples using CBC test which are commonly used in biomedical applications as MRI contrast agents and drug delivery.

\section{SYNTHESIS OF IRON OXIDE NANOPARTICLES}

Ferric chloride hexa-hydrate $\left(\mathrm{FeCl}_{3} \cdot 6 \mathrm{H}_{2} \mathrm{O}, 98.0 \%\right)$, Ferrous chloride tetra-hydrate $\left(\mathrm{FeCl}_{2} \cdot 4 \mathrm{H}_{2} \mathrm{O}, 99 \%\right)$, ammonium hydroxide $\left(\mathrm{NH}_{4} \mathrm{OH}\right)$ were obtained from Daejung Chemicals \& Metal Co. Korea. Iron oxide nanoparticles were prepared by co-precipitation method. Ferric chloride and ferrous chloride were mixed 2:1 ratio. The solution $(0.1 \mathrm{M})$ of $\mathrm{FeCl}_{3} \cdot 6 \mathrm{H}_{2} \mathrm{O},>98.0 \%$ and $0.05 \mathrm{M}$ solution of $\mathrm{FeCl}_{2} \cdot 4 \mathrm{H}_{2} \mathrm{O}, 99 \%$ were prepared. Both the solutions were mixed on magnetic stirrer plate at $40^{\circ} \mathrm{C}$ having $400 \mathrm{rpm}$. Approximately $20 \mathrm{ml}$ of $\mathrm{NH}_{4} \mathrm{OH}$ with a concentration of $25-28.0 \%$ added by drop up to the $\mathrm{pH}$ 9.5. The solution was stirred for additional 40 minutes without nitrogen environment. The solution color altered from orange to black, leading to a black precipitate. Finally centrifuged the solution at $4500 \mathrm{rev} / \mathrm{min}$ for $15 \mathrm{~min}$ to obtain $\mathrm{Fe}_{3} \mathrm{O}_{4}$ nanoparticles and dried in oven at $80{ }^{\circ} \mathrm{C}$ for approximately 24 hours. Chemical reaction has been shown in Eq. 6 as

$\mathrm{FeCl}_{2}+2 \mathrm{FeCl}_{3}+8 \mathrm{NH}_{4} \mathrm{OH} \rightarrow \mathrm{Fe}_{3} \mathrm{O}_{4}+8 \mathrm{NH}_{4} \mathrm{Cl}+4 \mathrm{H}_{2} \mathrm{O}$.

\section{RESULTS AND DISCUSSION}

\subsection{X-Ray Diffraction (XRD)}

XRD analysis of the magnetic nanoparticles was performed at Model PW 3710 operated at $45 \mathrm{kv}$ and $40 \mathrm{~mA}$ with a $\mathrm{Cu}-\mathrm{K} \alpha$ radiation. Five characteristic peaks marked by their Miller indices (2 00 0), (2 20 ), (3 11 1), (4 0 $0)$, ( $\left.\begin{array}{lll}4 & 4 & 0\end{array}\right)$ were identified which confirmed pure $\mathrm{Fe}_{3} \mathrm{O}_{4}$ nanoparticles. These peaks were found at $2 \theta$ degree range from $20^{\circ}$ to $80^{\circ}$ i.e. $21.23,30.47,35.57,43.37,62.81$ respectively which were mentioned in the Table 1. Scherer's formula indicated the formation of $\mathrm{Fe}_{3} \mathrm{O}_{4}$ nanoparticles with approximately $11.13 \mathrm{~nm}$ in diameter which were matched with reported data [15]. The average grain size of the $\mathrm{Fe}_{3} \mathrm{O}_{4}$ was calculated in the Table 2 using Scherer's formula.

$D=k \lambda / b \cos \theta$.

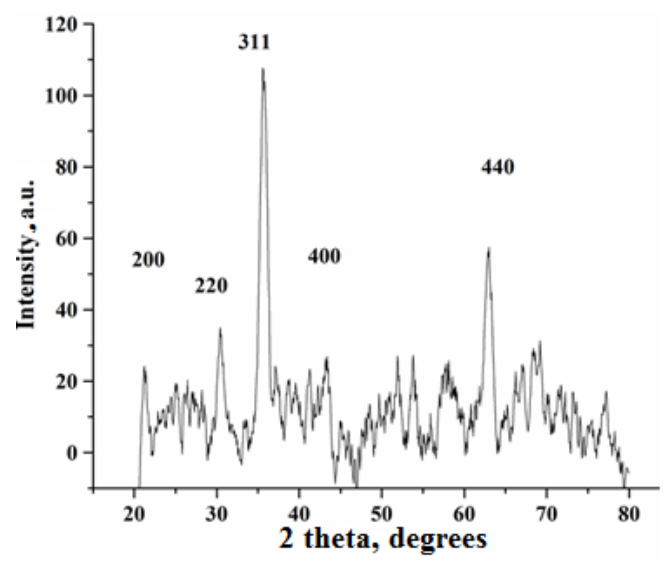

Fig. 1. XRD of superparamagnetic iron oxide nanoparticles [15]

Table 1. Miller indices calculation of $\mathrm{Fe}_{3} \mathrm{O}_{4}$

\begin{tabular}{|c|c|c|c|c|c|c|c|c|c|}
\hline S. No & $2 \theta$ & $\Theta$ & $\sin ^{2} \theta$ & $\sin ^{2} \theta / \sin ^{2} \theta_{\min i}$ & $\begin{array}{c}2 x \\
\sin ^{2} \theta / \sin ^{2} \theta_{\min i}\end{array}$ & $\begin{array}{c}3 x \\
\sin ^{2} \theta / \sin ^{2} \theta_{\min i}\end{array}$ & $\begin{array}{c}4 x \\
\sin ^{2} \theta / \sin ^{2} \theta_{\min i}\end{array}$ & $h^{2}+k^{2}+l^{2}$ & $h k l$ \\
\hline 1 & 21.23 & 10.62 & 0.0339 & 1 & 2 & 3 & 4 & 4 & 200 \\
\hline 2 & 30.47 & 15.24 & 0.0690 & 2.0 & 4 & 6 & 8 & 8 & 220 \\
\hline 3 & 35.57 & 17.79 & 0.0940 & 2.77 & 5.54 & 8.31 & 11 & 11 & 311 \\
\hline 4 & 43.37 & 21.74 & 0.1371 & 2.00 & 8 & 12 & 16 & 16 & 400 \\
\hline 5 & 62.81 & 31.40 & 0.2714 & 8.00 & 16 & 24 & 32 & 32 & 440 \\
\hline
\end{tabular}


Table 2. Calculation of average grain size of $\mathrm{Fe}_{3} \mathrm{O}_{4}$

\begin{tabular}{|c|c|c|c|c|c|c|c|c|}
\hline Peak & Plane & $(\lambda) \AA$ & $\begin{array}{c}\text { FWHM(B) } \\
\text { Rad }\end{array}$ & $\theta_{1}$ & $\theta_{2}$ & $\theta_{\text {в }}$ & $\cos \theta_{\mathrm{B}}$ & $\begin{array}{c}\text { Grain } \\
\text { size }\end{array}$ \\
\hline 1 & $(200)$ & 1.54 & 0.015 & 20.8 & 21.7 & 21.3 & 0.93 & 9.72 \\
\hline 2 & $(220)$ & 1.54 & 0.017 & 29.9 & 31.0 & 30.4 & 0.86 & 10.0 \\
\hline 3 & $(311)$ & 1.54 & 0.021 & 35.0 & 36.3 & 35.6 & 0.81 & 7.79 \\
\hline 4 & $(400)$ & 1.54 & 0.015 & 42.8 & 43.7 & 43.2 & 0.72 & 11.9 \\
\hline 5 & $(440)$ & 1.54 & 0.018 & 62.3 & 63.4 & 62.9 & 0.45 & 16.2 \\
\hline
\end{tabular}

Average grain size of iron oxide nanoparticles was $11.13 \mathrm{~nm}$ which was closer to the result calculated by Kulkarni SA. et al. [15.] The Miller indices showed the cubic structure of superparamagnetic iron oxides nanoparticles.

\subsection{Scanning Electron Microscopy (SEM)}

The morphology of the iron oxides nanoparticles was studied by using VEGA3 TESCAN, SEM machine at $20 \mathrm{KV}$. Samples were taken in powder form for SEM analysis. SEM images illustrated the spherical like particles shape. Surface of MNPs showed little aggregation on images as shown in Fig. 2. The basic chemistry of agglomeration in pure magnetite was due to the Van-dar Walls forces among the particles [16].

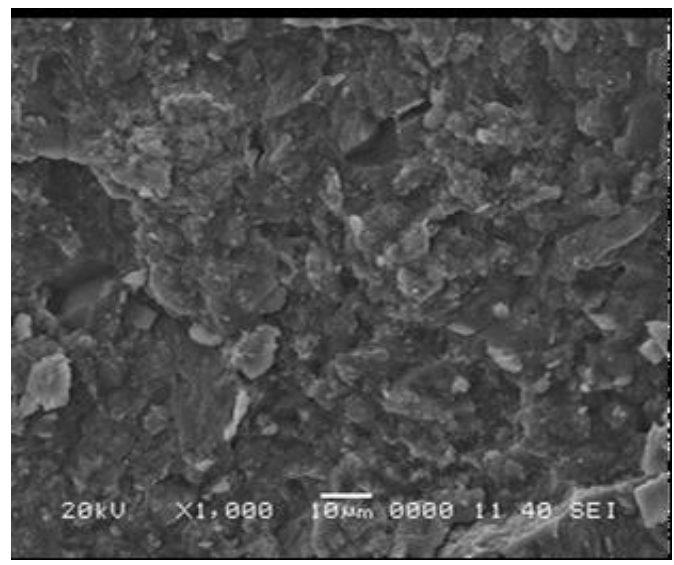

Fig. 2. $\mathrm{SEM}$ image of $\mathrm{Fe}_{3} \mathrm{O}_{4}$

\subsection{Energy Dispersion X-ray Spectroscopy (EDX) Analysis}

Iron oxide magnetic nanoparticles were scrutinized using VEGA3 TESCAN (SEM) and Oxford EDX detector. EDX study was used for quantitative analysis of MNPs (Mishra et. al, 2014). The EDX result showed the atomic percentage of different elements with weight percentage elements present in the sample. EDX technique explained the obtained peaks of each sample [17]. Fig. 3 showed Fe, $\mathrm{O}, \mathrm{C}$ and $\mathrm{Cl}$ peaks with $62.2,26.3,5.4$ and 5.9 weight $\%$ and 31.24, 47.86, 12.39 and 8.51 atomic \% which confirmed the pure iron oxide nanoparticles.

\subsection{Energy Dispersion X-ray Spectroscopy (EDX) Analysis}

The magnetic properties of MNPs were investigated by using a Dexing Magnet Tech Co, Limited (VSM-100). Magnetization curve of nanoparticles were at room temperature as shown in Fig. 4. Saturation magnetization $(M \mathrm{~s})$ of $\mathrm{Fe}_{3} \mathrm{O}_{4}$ was recorded $45.01 \mathrm{emu} / \mathrm{g}$. This value of saturation magnetization confirmed the results reported by Anbarasu et al. and Mahdavi et al. [18, 19].

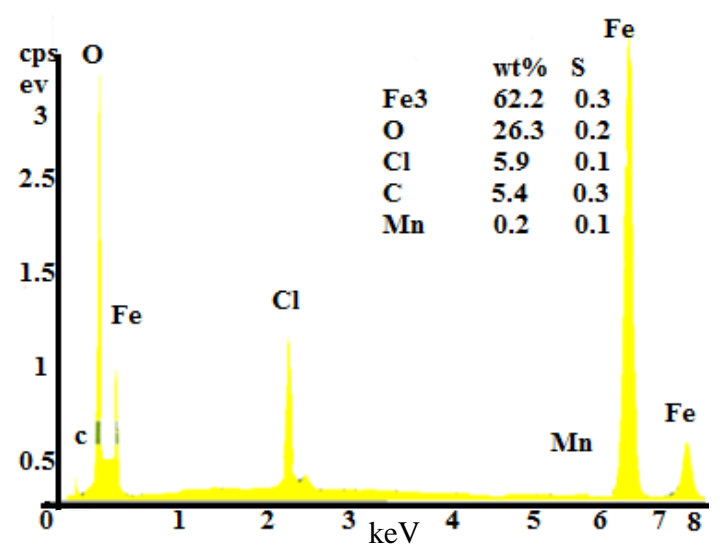

Fig. 3. EDX spectrum of $\mathrm{Fe}_{3} \mathrm{O}_{4}$

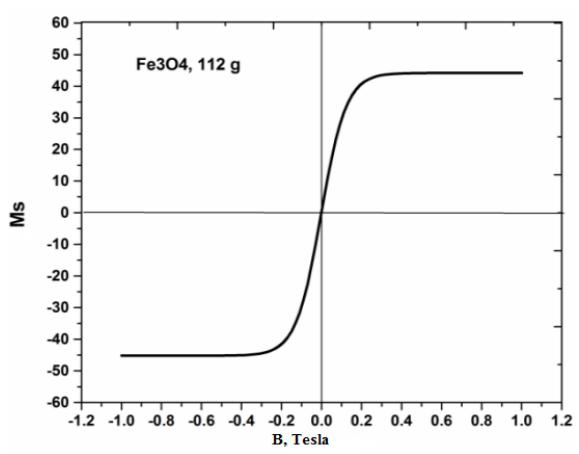

Fig. 4. Saturation magnetization $M \mathrm{~s}$ versus $B$

\subsection{Hematology analysis}

In this study, CBC test of normal and diabetic blood samples was performed at hematology analyzers for $0 \mathrm{hrs}$, $2 \mathrm{hrs}, 4 \mathrm{hrs}, 8 \mathrm{hrs}, 24 \mathrm{hrs}, 48 \mathrm{hrs}$ and $72 \mathrm{hrs}$ respectively in Medical Lab Technology, Haripur, Pakistan. Blood samples were collected from normal and diabetic patients in $\mathrm{K}_{2}$-EDTA tubes, which were stored at $4{ }^{\circ} \mathrm{C}$. For precise testing manufacturer linearity ranges were also verified for erythrocytes, leucocytes and thrombocytes and hemoglobin. To start test, the blood was warmed at room temperature. Magnetic nano particles in fine powder $3 \mathrm{mg}$ were mixed in $5 \mathrm{dl}$ of each blood sample in EDTA tubes before $\mathrm{CBC}$ test. A significant decrease in hemoglobin, erythrocytes, leucocytes and thrombocytes was found due to toxic effect of the iron oxide in blood samples. The oxygen based radicals including hydroxyl radicle, singlet oxygen and hydrogen peroxide interacted with the cell membrane and caused to cell death [20, 21]. In fact, hydroxyl radicals were generated due to Haber-Weiss reaction of iron which initiated the lipid peroxidation to blood cells and finally cell death [22].

Hematology histogram of erythrocytes, leucocytes and thrombocytes histograms was shown in Fig. 5. The vertical axis showed the cell count and horizontal axis presented the cell volume. RBCs measured for normal $\mathrm{O}$-ve subjects were $4.74 \times 10^{12} / \mathrm{dL}$ at $0 \mathrm{hrs}$ that found in normal range of $3.50-5.50 \times 10^{12} / \mathrm{L}$. Platelet counts were $309 \times 10^{9} / \mathrm{dL}$ for $\mathrm{AB}+$ healthy subject at $0 \mathrm{hrs}$ which was in the range of $150-450 \times 10^{9} / \mathrm{dL}$. WBCs count for B -ve diabetic subject 
were $9.6 \times 10^{9} / \mathrm{L}$ at $0 \mathrm{hrs}$ which lies in the range $4.0-$ $10 \times 10^{9} / \mathrm{dL}$.

The vertical axis showed the cell count and horizontal axis presented the cell volume. RBCs measured for normal $\mathrm{O}$-ve subjects were $4.74 \times 10^{12} / \mathrm{dL}$ at $0 \mathrm{hrs}$ that found in normal range of $3.50-5.50 \times 10^{12} / \mathrm{L}$. Platelet counts were $309 \times 10^{9} / \mathrm{dL}$ for $\mathrm{AB}+$ healthy subject at $0 \mathrm{hrs}$ which was in the range of $150-450 \times 10^{9} / \mathrm{dL}$. WBCs count for $\mathrm{B}-\mathrm{ve}$ diabetic subject were $9.6 \times 10^{9} / \mathrm{L}$ at $0 \mathrm{hrs}$ which lies in the range $4.0-10 \times 10^{9} / \mathrm{dL}$. Diabetic Blood Groups $\mathrm{B}^{-}$ (287 mg/dL), B ${ }^{+}(282 \mathrm{mg} / \mathrm{dL}), \quad$ O- $(335 \mathrm{mgL} / \mathrm{dL}), \quad \mathrm{O}+$ $(331 \mathrm{mg} / \mathrm{dL}), \quad \mathrm{AB}+(372 \mathrm{mg} / \mathrm{dl})$ were pathologically evaluated $[23,24]$.

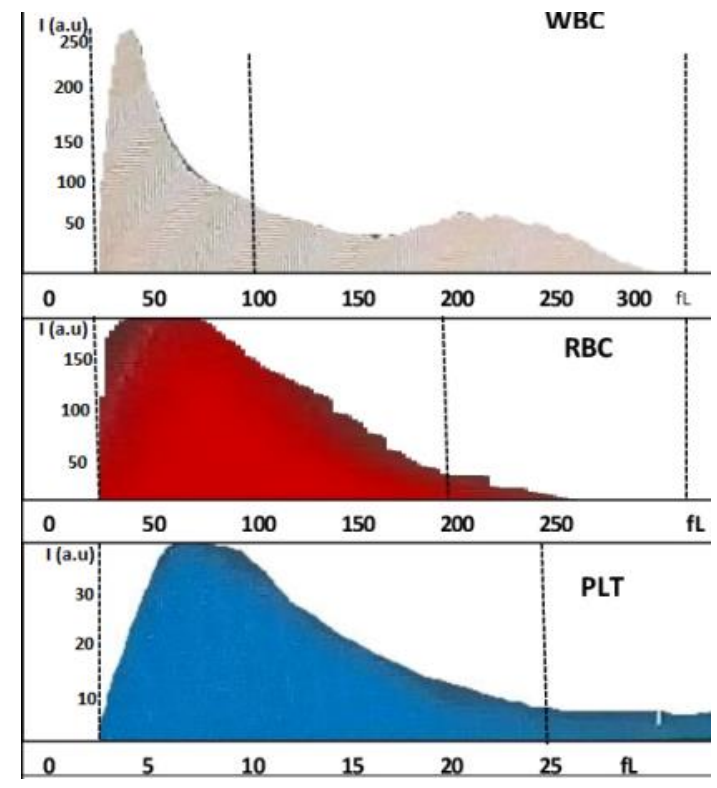

Fig. 5. Hematology histogram of White Blood Cell (WBC), Red Blood Cell (RBC) and Platelets (PLT)

Table 3. CBC results of healthy blood groups, $\mathrm{mg} / \mathrm{dL}$

\begin{tabular}{|c|c|c|c|c|c|c|c|c|c|c|}
\hline S.n & BG & $\overline{\mathrm{CBC}}$ & $0 \mathrm{hr}$ & $2 \mathrm{hr}$ & $4 \mathrm{hr}$ & $8 \mathrm{hr}$ & $24 \mathrm{hr}$ & $48 \mathrm{hr}$ & $72 \mathrm{hr}$ & $\mathrm{P}=0.05$ \\
\hline \multirow{4}{*}{1} & & $\mathrm{Hb}$ & 12.1 & 11.3 & 11 & 10 & 9.9 & 9.4 & 9.3 & 0.71 \\
\hline & & Wbc & 6.9 & 6.4 & 6.1 & 5.7 & 5.2 & 5.1 & 4.8 & 0.79 \\
\hline & & $\mathrm{Rb}$ & 5.01 & 4.81 & 4.76 & 4.61 & 3.95 & 3.41 & 3.12 & 0.22 \\
\hline & & Plt & 241 & 223 & 191 & 157 & 143 & 129 & 101 & 0.92 \\
\hline \multirow{4}{*}{12} & \multirow{4}{*}{+} & $\mathrm{Hb}$ & 9 & 8.8 & 7.9 & 7.2 & 6.6 & 6.4 & 6.3 & 0.23 \\
\hline & & Wbc & 7.5 & 6.9 & 6.5 & 6.2 & 5.5 & 5.1 & 4.8 & 0.86 \\
\hline & & $\mathrm{Rb}$ & 5.29 & 4.95 & 4.83 & 4.74 & 3.96 & 3.93 & 3.92 & 0.12 \\
\hline & & Plt & 193 & 171 & 164 & 141 & 123 & 115 & 106 & 0.69 \\
\hline \multirow{4}{*}{3} & & $\mathrm{Hb}$ & 14.6 & 12 & 11.3 & 9.9 & 9.5 & 6.6 & 5.1 & 0.93 \\
\hline & & Wbc & 5.1 & 4.8 & 4.1 & 4.6 & 3.9 & 3.1 & 1.4 & 0.23 \\
\hline & & $\mathrm{Rb}$ & 4.74 & 3.94 & 3.88 & 3.84 & 3.76 & 3.73 & 3.62 & \begin{tabular}{|l|}
0.007 \\
\end{tabular} \\
\hline & & Plt & 182 & 150 & 142 & 125 & 101 & 98 & 85 & 0.75 \\
\hline \multirow{4}{*}{4} & \multirow{4}{*}{$\mathrm{O}+$} & $\mathrm{Hb}$ & 13.3 & 10 & 9.5 & 8.8 & 8.3 & 7.4 & 7.2 & 0.22 \\
\hline & & $\mathrm{Wbc}$ & 12.3 & 10.4 & 9.9 & 8.9 & 8.1 & 7.8 & 5.1 & 0.97 \\
\hline & & $\mathrm{Rb}$ & 6.23 & 5 & 4.93 & 4.82 & 4.61 & 4.49 & 4.23 & \begin{tabular}{|l|}
0.100 \\
\end{tabular} \\
\hline & & Plt & 298 & 286 & 213 & 191 & 162 & 148 & 136 & 0.26 \\
\hline \multirow{4}{*}{5} & \multirow{4}{*}{$\mathrm{AB}+$} & $\mathrm{Hb}$ & 8.1 & 7.6 & 7.3 & 7.1 & 6.9 & 6.5 & 6.2 & 0.99 \\
\hline & & Wbc & 11.3 & 10.5 & 8.8 & 7.7 & 7.2 & 6.9 & 6 & 0.56 \\
\hline & & $\mathrm{Rb}$ & 5.58 & 5.35 & 5.15 & 5.05 & 4.78 & 4.66 & 4.31 & 0.99 \\
\hline & & Plt & 309 & 299 & 280 & 268 & 241 & 238 & 225 & 0.60 \\
\hline
\end{tabular}

Table 3 and Table 4 have demonstrated the decrease in blood samples of healthy subjects as well as diabetic blood samples that were shown in Fig. 6.

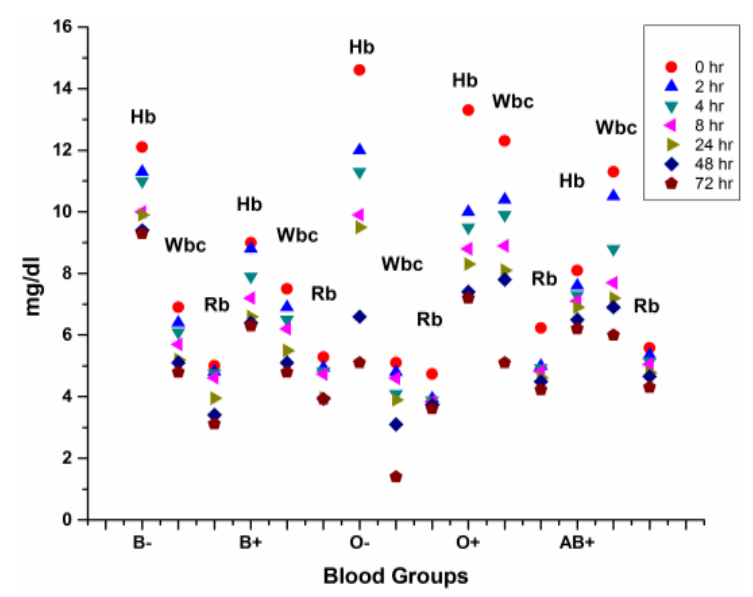

a

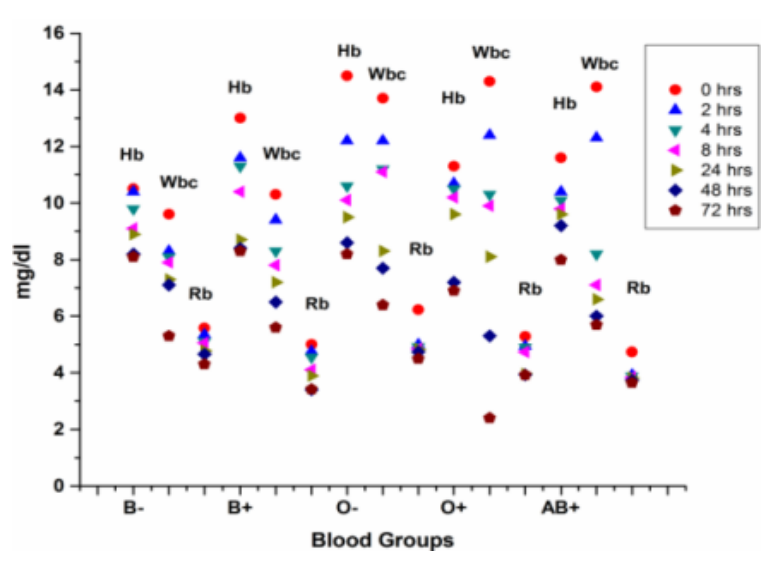

b

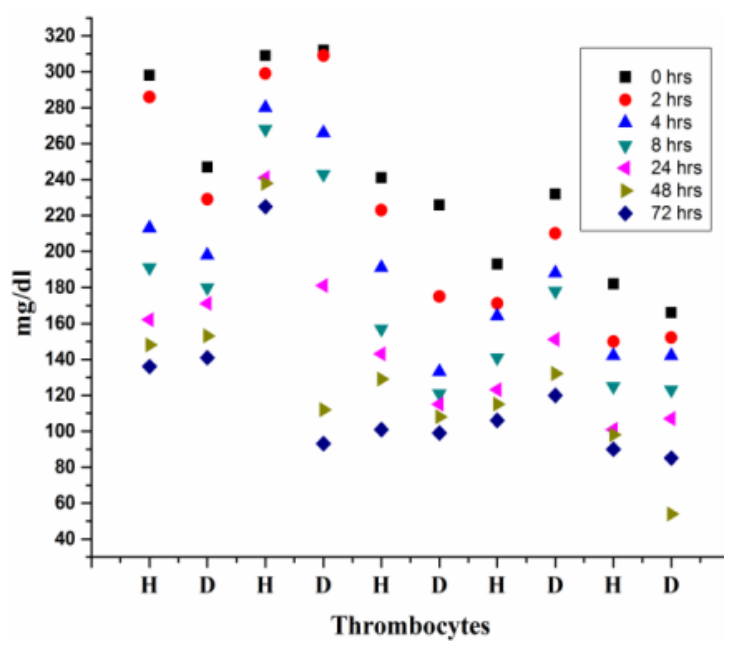

c

Fig. 6. Hematology test analysis: a-hemoglobin, RBC, WBCs in healthy blood samples; $b$-hemoglobin, RBC, WBCs in diabetic blood samples; $\mathrm{c}$-thrombocytes in healthy and diabetic blood samples 
Table 4. CBC results of diabetic blood samples, $\mathrm{mg} / \mathrm{dL}$

\begin{tabular}{|c|c|c|c|c|c|c|c|c|c|c|}
\hline$\overline{. N}$ & $\overline{\mathrm{BG}}$ & $\mathrm{CBC}$ & $0 \mathrm{hr}$ & $2 \mathrm{hr}$ & $4 \mathrm{hr}$ & $8 \mathrm{hr}$ & $24 \mathrm{hr}$ & $48 \mathrm{hr}$ & $2 \mathrm{hr}$ & $=0.0$ \\
\hline \multirow{4}{*}{1} & \multirow{4}{*}{ B } & $\mathrm{Hb}$ & 10.5 & 10.4 & 9.8 & 9.1 & 8.9 & 8.2 & 8.1 & 0.40 \\
\hline & & Wbc & 9.6 & 8.3 & 8.1 & 7.9 & 7.3 & 7.1 & 5.3 & 0.77 \\
\hline & & $\mathrm{Rb}$ & 5.58 & 5.35 & 5.11 & 5.05 & 4.78 & 4.66 & 4.31 & 0.99 \\
\hline & & Plt & 226 & \begin{tabular}{|l}
175 \\
\end{tabular} & 133 & 121 & \begin{tabular}{|l|}
115 \\
\end{tabular} & \begin{tabular}{|l|}
108 \\
\end{tabular} & 99 & 0.32 \\
\hline \multirow{4}{*}{ 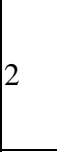 } & \multirow{4}{*}{$\mathrm{B}+$} & $\mathrm{Hb}$ & 13 & 11.6 & 11.3 & 10.4 & \begin{tabular}{|l}
8.7 \\
\end{tabular} & 8.4 & 8.3 & 0.35 \\
\hline & & Wbc & 10.3 & 9.4 & 8.3 & 7.8 & 7.2 & 6.5 & 5.6 & 0.98 \\
\hline & & $\mathrm{Rb}$ & 5.01 & 4.75 & 4.55 & 4.11 & 3.9 & 3.41 & 3.42 & 0.52 \\
\hline & & Plt & 232 & 210 & 188 & 178 & 151 & 132 & 120 & 0.05 \\
\hline & \multirow{4}{*}{ O- } & $\mathrm{Hb}$ & 14.5 & 12.2 & 10.6 & \begin{tabular}{|l|}
10.1 \\
\end{tabular} & 9.5 & 8.6 & 8.2 & 0.49 \\
\hline & & Wbc & \begin{tabular}{|l|}
13.7 \\
\end{tabular} & 12.2 & 11.2 & \begin{tabular}{|l|}
11.1 \\
\end{tabular} & 8.3 & 7.7 & 6.4 & 0.69 \\
\hline & & $\mathrm{Rb}$ & 6.23 & 5 & 4.93 & 4.85 & 4.82 & 4.74 & 4.5 & 0.01 \\
\hline & & Plt & 166 & 152 & 142 & 123 & 107 & 54 & 85 & 0.10 \\
\hline & \multirow{4}{*}{$\mathrm{O}+$} & $\mathrm{Hb}$ & 11.3 & 10.7 & 10.5 & 10.2 & 9.6 & 7.2 & 6.9 & 0.11 \\
\hline & & Wbc & 14.3 & 12.4 & 10.3 & 9.9 & 8.1 & 5.3 & 2.4 & 0.92 \\
\hline & & $\mathrm{Rb}$ & 5.29 & 4.95 & 4.9 & 4.74 & 3.96 & 3.93 & 3.92 & 0.11 \\
\hline & & Plt & 247 & 229 & 198 & 180 & \begin{tabular}{|l|}
171 \\
\end{tabular} & \begin{tabular}{|l|}
153 \\
\end{tabular} & 141 & 0.05 \\
\hline & \multirow{4}{*}{$\mathrm{AB}+$} & $\mathrm{Hb}$ & 11.6 & 10.4 & \begin{tabular}{|l|}
10.1 \\
\end{tabular} & 9.8 & \begin{tabular}{|l|}
9.6 \\
\end{tabular} & 9.2 & 8 & 0.95 \\
\hline & & Wbc & 14.1 & 12.3 & 8.2 & 7.1 & 6.6 & 6.0 & 5.7 & 0.08 \\
\hline & & $\overline{\mathrm{Rb}}$ & 4.74 & 3.92 & 3.88 & 3.84 & 3.82 & 3.73 & 3.65 & 0.00 \\
\hline & & Plt & 312 & 309 & 266 & 243 & 181 & 112 & 93 & 0.10 \\
\hline
\end{tabular}

\section{CONCLUSIONS}

One sample test of variance revealed a significant reduction of hemoglobin, erythrocytes, leucocytes and thrombocytes in complete blood count within normal and diseased blood groups at specified time period. This study concluded that presence of iron oxides nanoparticles of size $11.5 \mathrm{~nm}$ in human blood induces reactive oxygen species which cause the cell death. Hemoglobin was highly affected content of blood than erythrocytes, leucocytes by toxic effects of iron oxides nanoparticles. Reduction of platelets among all content of blood groups posed another signature of this hematology study. Toxic spectrum of iron oxides nanoparticles must also be considered before the fruitful application of MRI contrast agents and drug delivery.

\section{Acknowledgments}

We are thankful to Eng. Usman Ayub, Biomedical Lab \& Technology, Haripur who helped us in CBC of blood samples.

\section{REFERENCES}

1. Oh, J.K., Park, JM. Iron Oxide-Based Superparamagnetic Polymeric Nanomaterials: Design, Preparation, And Biomedical Application Progress in Polymer Science 36 (1) 2011: pp.168-189.

https://doi.org/10.1016/j.progpolymsci.2010.08.005

2. Lara, Y., Nguyen, T., Marilena, L., Alexander, M. Toxicological Considerations of Clinically Applicable Nanoparticles NanoToday 6(6) 2011: pp.585-607. https://doi.org/10.1016/j.nantod.2011.10.001

3. Oznur, K., Hakan, K., Seda, B. A Simple Way Synthesize Superparamagnetic Iron Oxide Nano Particles in Air Amosphere: Iron Ion Concentration Effect. IEEE Transctions on Magnetics 46 (12) 2010: pp. 3978-3983. https://doi.org/10.1109/TMAG.2010.2076824

4. Arias, L.S., Pessan, J.P., $\quad$ Vieira, A.P.M., de Lima, T.M. T., Delbem, A.C.B., Monteiro, D.R. Iron
Oxide Nanoparticles for Biomedical Applications: A Perspective on Synthesis, Drugs, Antimicrobial Activity and Toxicity Antibiotics 7 (46) 2018: pp. 1-32. http://doi.org/10.3390/antibiotics7020046

5. Baumjohann, D., Hess, A., Budinsky, L., Brune, K., Schuler, G., Lutz, M.B. In Vivo Magnetic Resonance Imaging of Dendritic Cell Migration into the Draining Lymph Nodes of Mice European Journal of Immunology 36 (9) 2006: pp. 2544-2555. https://doi.org/10.1002/eji.200535742

6. Ray, P.C., Yu, H., Fu, P.P. Toxicity and Environmental Risks of Nanomaterials: Challenges and Future Needs Journal of Environmental Science and Health Part C 27 (1) 2009: pp. $1-35$. http://doi.org/10.1080/10590500802708267

7. Namara, K., Tofail, S.A. Nanoparticles in Biomedical Applications Advances in Physics: $X$. 2(1) 2017: pp. $54-88$.

8. Oberdörster, G., $\quad$ Maynard, A., $\quad$ Donaldson, K., Castranova, V., Fitzpatrick, J., Ausman, K., Carter, J., Karn, B., Kreyling, W., Lai, D., Olin, S. Principles for Characterizing the Potential Human Health Effects from Exposure to Nanomaterials: Elements of a Screening Strategy Particle and Fibre Toxicology 2(1) 2005: pp. $2-8$. https://doi.org/10.1186/1743-8977-2-8.

9. Augusto, O., Miyamoto, S., Pantopoulos, K, Schipper, H. Principles of Free Radical Biomedicine. Oxygen Radicals and Related Species. São Paulo, Nova Science Publishers, 2011: pp. $1-23$.

10. Fu, P.P., Xia, Q., Hwang, H.M., Ray, P.C., Yu, H. Mechanisms of Nano toxicity: Generation of Reactive Oxygen Species Journal of Food and Drug Analysis 22 (1) 2014: pp. 64-75. https://doi.org/10.1016/j.jfda.2014.01.005

11. Wu, H., Yin, J.J., Wamer, W.G., Zeng, M., Lo, YM. Reactive Oxygen Species-Related Activities of Nano-Iron Metal and Nano-Iron Oxides Journal of Food and Drug Analysis 22 (1) 2014: pp. 86-94. https://doi.org/10.1016/j.jfda.2014.01.007

12. Puzyn, T., Rasulev, B., Gajewicz, A. Using Nano-QSAR to Predict the Cytotoxicity of Metal Oxide Nanoparticles Nature Nanotechnology 6 (3) 2011: pp. 175-178. https://doi.org/10.1038/nnano.2011.10

13. Oberdörster, G., Stone, V., Donaldson, K. Toxicology of Nanoparticles: A Historical Perspective Nanotoxicology 1 (1) 2007: pp. $2-5$. https://ci.nii.ac.jp/naid/10027434218/en/

14. Brunner, T.J., Wick, P., Manser, P., Spohn, P., Grass, R.N., Limbach, L.K., Bruinink, A., Stark, W.J. In Vitro Cytotoxicity of Oxide Nanoparticles: Comparison to Asbestos, Silica, and the Effect of Particle Solubility Environmental science \& Technology 40 (14) 2006: pp. 4374-4381. https://doi.org/10.1021/es052069i

15. Kulkarni, S.A., Sawadh, P.S., Palei, P.K., Kokate, K.K. Effect of Synthesis Route on the Structural, Optical and Magnetic Properties of $\mathrm{Fe} 3 \mathrm{O} 4$ Nanoparticles Ceramics International 40 (1) 2014: pp. 1945-1949. https://doi.org/10.1016/j.ceramint.2013.07.103

16. Higgins, JM. Red Blood Cell Population Dynamics Clinics in Laboratory Medicine 35 (1) 2015: pp. 43-57. https://doi: 10.1016/j.cll.2014.10.002 
17. Chaudhury, A., Noiret, L., Higgins, J.M. White Blood Cell Population Dynamics for Risk Stratification of Acute Coronary Syndrome Proceedings of the National Academy of Sciences 27 2017: pp. 1-6. https://doi.org/10.1073/pnas.1709228114

18. Anbarasu, M., Anandan, M., Chinnasamy, E., Gopinath, V., Balamurugan, $\mathbf{K}$. Synthesis and Characterization of Polyethylene glycol (PEG) coated Fe3O4 Nanoparticles by Chemical Co-precipitation Method for Biomedical Applications Spectrochimica Acta Part A: Molecular and Biomolecular Spectroscopy 135 (25) 2015: pp. 536-539 https://doi.org/10.1016/j.saa.2014.07.059

19. Mahdavi, M., Ahmad, M.B., Haron, M.J., Namvar, F., Nadi, B., Rahman, M.Z.A., Amin, J. Synthesis, Surface Modification and Characterisation of Biocompatible Magnetic Iron Oxide Nanoparticles for Biomedical Applications Molecule 18 (7) 2013: pp. 7533-7548. https://doi.org/10.3390/molecules 18077533

20. Sharafi, A., Seyedsadjadi, M. Surface-Modified Superparamagnetic Nanoparticles $\mathrm{Fe}_{3} \mathrm{O}_{4}$, PEG for Drug Delivery Magnetic Resonance Imaging 2013: pp. 4-6.

21. Hoskins, C., Cuschieri, A., Wang, L. The cytotoxicity of polycationic iron oxide nanoparticles: common endpoint assays and alternative approaches for improved understanding of cellular response mechanism Journal of Nanobiotechnology 10 (1) 2012: pp. 10-15. https://doi.org/10.1186/1477-3155-10-15

22. Wydra, R.J., Rychahou, P.G.,

Evers, B.M., Anderson, K.W., Dziubla, T.D., Hilt, J.Z. The role of ROS generation from magnetic nanoparticles in an alternating magnetic field on cytotoxicity Acta Biomaterialia 25 2015: pp. $284-290$.

https://doi.org/10.1016/j.actbio.2015.06.037

23. Feng, Q., Liu, Y., Huang, J., Chen, K., Huang, J., Xiao, K. Uptake, distribution, clearance, and toxicity of iron oxide nanoparticles with different sizes and coatings Scientific Reports 8 (1) 2018: pp. 1-12. https://doi.org/10.1038/s41598-018-19628-z https://doi.org/10.1016/j.jhazmat.2012.03.083

24. Yang, Y., Qin, Z., Zeng, W., Yang, T., Cao, Y., Mei, C., Kuang, Y. Toxicity assessment of nanoparticles in various systems and organs Nanotechnology Reviews $6(3)$ 2017: pp. $279-289$. https://doi.org/10.1515/ntrev-2016-004 